\title{
APOCALYPSE NOW? FUNDAMENTAL \\ TAX REFORM AND RESIDENTIAL \\ HOUSING VALUES
}

Donald Bruce

Douglas Holtz-Eakin

Working Paper 6282 


\title{
APOCALYPSE NOW? FUNDAMENTAL TAX REFORM AND RESIDENTIAL HOUSING VALUES
}

\author{
Donald Bruce \\ Douglas Holtz-Eakin
}

Working Paper 6282

http://www.nber.org/papers/w6282

\section{NATIONAL BUREAU OF ECONOMIC RESEARCH 1050 Massachusetts Avenue \\ Cambridge, MA 02138 \\ November 1997}

\begin{abstract}
We thank James Follain, Patric Hendershott, William Gale, and James Poterba for useful comments on an earlier draft; the Center for Policy Research, Syracuse University for research support; and Esther Gray for her aid in preparing the manuscript. Any opinions expressed are those of the authors and not those of the National Bureau of Economic Research.

(C) 1997 by Donald Bruce and Douglas Holtz-Eakin. All rights reserved. Short sections of text, not to exceed two paragraphs, may be quoted without explicit permission provided that full credit, including (C) notice, is given to the source.
\end{abstract}


Apocalypse Now? Fundamental Tax Reform

and Residential Housing Values

Donald Bruce and Douglas Holtz-Eakin

NBER Working Paper No. 6282

November 1997

JEL No. $\mathrm{H} 24$

\begin{abstract}
Using a simulation model crafted to integrate the short-run and long-term impacts of tax reform on the housing market, we find modest impacts from fundamental reform of the Federal income tax. These results suggest that concerns over the impact of tax reform on housing values and household net worth are overstated. To the extent that reform is otherwise desirable, fears of drastic effects on the housing market should not stand as an impediment to reform.
\end{abstract}

Donald Bruce

Center for Policy Research

426 Eggers Hall

Syracuse University

Syracuse, NY 13244-1090

djbruce@maxwell.syr.edu
Douglas Holtz-Eakin

Center for Policy Research

426 Eggers Hall

Syracuse University

Syracuse, NY 13244-1090

and NBER

djheakin@maxwell.syr.edu 


\section{INTRODUCTION}

Recent years have witnessed numerous calls for overhaul of the Federal income tax. The most dramatic of these proposals seek to replace the income tax with a comprehensive consumption-based tax. Inter alia, such reforms would eliminate the tax-favored status of owner-occupied housing, leading some commentators to raise the specter of a massive decline in housing values, substantial windfall losses in the housing wealth of U.S. households, and largescale defaults on mortgage obligations. For example, in a widely-publicized study, Data Resources Incorporated (DRI) predicted an apocalyptic fall in housing values, estimating that the Flat Tax (one consumption-based alternative) would result in an aggregate decline of 15 percent in housing values, equivalent to a loss of $\$ 1.7$ trillion in housing equity (see Brinner et al. [1995]).

Fears of massive housing price impacts could serve as a severe impediment to reform. But are they justified? In some sense, downward pressure on residential housing values would be inescapable. Comprehensive consumption taxation would both eliminate the existing taxsubsidies to owner-occupied housing and also tax its use. It is straightforward to expect households to reduce their demand for owner-occupied housing. But the DRI analysis does not embody such a reaction. Instead, the forecast $\$ 1.7$ trillion decline in housing values is simply the present value of the benefits lost by elimination of the mortgage interest and property tax deductions. $^{1}$

In a related analysis, Capozza, Green, and Hendershott [1996] (hereafter, CGH) reach conclusions similar to those of DRI. CGH assume that the user-cost of owner-occupied housing is unchanged by reform, and calculate the change in housing values consistent with this assumption. However, if the rental price is unchanged, the long-run quantity demanded must 
also remain fixed. Thus, the assumptions employed imply that the size of the housing sector will be completely unaffected by fundamental tax reform.

Our purpose is to revisit the impact of consumption tax reform on housing values in a setting consistent with both a downward-sloping demand for housing services and rational valuation of houses as assets. Moreover, it is desirable to distinguish between the transitory response of the housing market to tax reform and the longer term (steady-state) implications. To accomplish our goals, we develop a dynamic, perfect foresight simulation model of the residential housing sector. The model is tailored to identify the aggregate impacts, tracing the intertemporal interaction between demands derived from a representative household and supplies based upon a Tobin's $q$ model of new construction.

In this setting, it is possible that a consumption tax reform would raise the value of existing homes. To see why, consider a scenario in which individuals do not itemize deductions of mortgage interest or property taxes (which is the case for 40 percent of homeowners) and in which the consumption tax takes the form of a 20 percent value-added tax (VAT). Eliminating deductibility would, obviously, have no direct impact on existing homeowners, while the VAT would raise the cost of new homes by 20 percent. Older, existing homes would enjoy a tax-based advantage of 20 percent, leading to a rise in their value, ceteris paribus. Over the longer term, construction activity would eliminate the distinction between existing and new homes, and the price differential along with it. But during the transition, the tax reform would have the perhaps surprising effect of enhancing the value of older homes. To the extent that households itemize, the loss of deductibility mitigates this effect, but the underlying tendency remains.

The remainder is organized as follows. In Section 2 we develop our model of the housing sector, while in Section 3 we discuss the parameterization of our simulation model and 
alternative strategies to implementing consumption-based tax reform. Section 4 contains our results, the bulk of which suggest a relatively modest impact of tax reform on housing values.

In Section 5 we examine the sensitivity of our baseline results to a number of alternative assumptions, especially the role of land in the production of housing and the dynamic adjustment of housing prices.

\section{MODELING THE RESIDENTIAL HOUSING SECTOR}

We require a model capable of delivering both the long-run predictions from fundamental tax reform, as well as the explicit dynamic path for the value of housing during the transition to the new long-run equilibrium (steady state). In developing our model, we build upon the work of Summers [1983] and Poterba [1984].

To begin, we observe that housing serves the dual role of consumption good and investment vehicle. The latter requires that homeowners be indifferent between holding their house and investing in an alternative asset. That is, asset market equilibrium requires that

$$
i(1-\tau)=\frac{\frac{S}{H}-\left[t_{p}(1-\tau)+\delta+m\right] P_{H}+\dot{P}_{H}}{P_{H}}
$$

where $i$ is the nominal rate of interest, $\tau$ is the individual's marginal income tax rate, $S$ is the annual implicit service flow (imputed rent) from ownership, $H$ is the amount of housing, $t_{p}$ is the property tax rate, $\delta$ is the percentage rate of depreciation, $m$ is the percentage rate of maintenance costs, $P_{H}$ is the price of a house, and the dot "." denotes a derivative with respect to time. In effect, (2.1) displays the requirement that the return (imputed rent plus capital gain) on housing net of property tax, depreciation, and maintenance costs be equal to the net return on an alternative investment. 
It is useful to transform (2.1) in several ways. First, in the spirit of Tobin's $q$ theory of investment, define $Q_{H}$ as the ratio of housing value to replacement cost, with the latter normalized to 1.0 per house. Thus, $Q_{H}=\left(P_{H} H\right) / H=P_{H}$. Second, assuming equilibrium in the market for housing services, let the annual service flow be a function of the housing stock

$$
S=S(H)
$$

Finally, substitute (2.2) into (2.1) and solve for the change in $Q_{H}$ necessary to maintain asset market equilibrium. The result

$$
\dot{Q}_{H}=\left[i(1-\tau)+t_{p}(1-\tau)+\delta+m\right] Q_{h}-\frac{S(H)}{H}
$$

allows one to track the equilibrium dynamics of the price of housing relative to its replacement cost. Equation (2.3) ignores the distinction between equity and mortgage financing costs, assumes that all interest and property taxes are fully deducted, and assumes that interest income is fully taxable. We can relax these assumptions. Let $\beta$ denote the loan-to-value ratio, $\theta$ the portion of financing costs that are deductible, $\gamma$ the fraction of property taxes that are deductible, and $e$ the portion of interest income that is taxable. Equation (2.3) then becomes

$$
\dot{Q}_{H}=\left(i[\beta(1-\theta \tau)+(1-\beta)(1-e \tau)]+t_{p}(1-\gamma \tau)+\delta+m\right) Q_{h}-\frac{S(H)}{H}
$$

Viewed as one part of a system of equations describing housing market dynamics, (2.3') shows the relationship between current values of housing values $\left(Q_{H}\right)$ and quantities $(H)$ and future changes in the price of housing.

To completely describe the evolution of the market requires a dynamic model of housing supply. We assume that new construction $(C)$ is an increasing function of the ratio of market value to replacement cost. That is

$$
C \equiv \dot{H}=C\left(Q_{H}\right) H
$$


where $C(1)=0$.

Taken together (2.3') and (2.4) comprise a standard asset market-oriented model of tax incidence in the spirit of Summers [1983] and provide a setting within which to analyze the transitional dynamics of the housing market. A convenient means to do so is the phase-diagram in Figure 1. In this figure, the steady state is at $H^{*}$ and $Q_{H}{ }^{*}$ (where market value equals replacement cost, i.e., $Q_{H}{ }^{*}=1$ ). In itself, the steady state is not very interesting-the long-run price of houses is simply the exogenous replacement cost. There are, however, some interesting dynamics present. The transition to the steady state is shown by the saddle path marked with arrows and permits short-run fluctuations in the asset price of houses.

To gain a feel for the analysis, consider the scenario discussed earlier. Specifically, assume that there is no deductibility of mortgage interest or property taxes and that a consumption tax is imposed via a business level tax such as a VAT or the Flat Tax. The key feature of such a reform is that the tax on residential housing is imposed solely on new construction and not on existing housing. Specifically, it raises the "break-even" value of a new home from 1.0 to $(1+\mathrm{t})$, where $\mathrm{t}$ is the consumption tax rate. Thus, the long-run value of $Q_{H}$ rises from $Q_{H}^{*}=1$ to $Q_{H}^{\prime}=1+t$; that is, in (2.4) $C(1+t)=0$. As shown in Figure 2 , the $\dot{Q}_{H}=0$ locus is unaffected, while the $\dot{H}=0$ locus shifts upward.

As a result, the steady state level of $H$ declines to $H^{\prime}$; exactly what one would expect when a tax on housing is introduced. However, the transition to the new steady state takes place in two steps. Instantaneously, the value of $H$ is fixed; the market adjusts to the need for making the transition by having $P_{H}$ (and $Q_{H}$ ) jump up at the existing housing stock (from A to B). Intuitively, old houses are more valuable because they do not face the consumption tax; people will bid up the price of such houses until they are indifferent between the existing stock and the 
new, taxed housing. ${ }^{2}$ In the aftermath, housing prices move to the long-run equilibrium and the size of the residential sector shrinks as the market evolves toward the new steady state (B to C).

In short, in the absence of deductibility, the transition to this consumption-based tax on new houses leads to a short-run rise in house values. However, the example ignores several features of reality, most notably deductibility of mortgage interest and property tax payments. How does deductibility affect the analysis? The major difference is that removing deductibility applies to both new and old houses. As shown in Figure 3, removing deductibility alone results in a downward shift in the $\dot{Q}_{H}=0$ locus. Thus, in contrast to the example above, removing deductibility results in an immediate fall in housing values, and a subsequent transition to a new steady state that has lower quantities of housing and a recovery of housing values to $Q_{H}=1$.

Taking Figures 2 and 3 together, the transition from the current system to a consumptionbased tax system has an ambiguous effect on housing values. Moreover, to the extent that values either rise or fall, the persistence of these effects will depend upon the speed of adjustment embodied in the dynamics of housing supply (equation (2.4)). Thus, the sign, size and duration of the net effect may be determined only by a quantitative evaluation, to which we now turn.

\section{SIMULATING TAX REFORM}

Consumption-based tax reforms could be implemented in a variety of ways. The most direct is a national retail sales tax which would entail a tax on the purchase of a new home, raising its price. ${ }^{3}$ Similarly, the consumption tax could be implemented as a VAT; again the reform would appear in the housing market as a tax on transactions in the construction and sale of new homes. ${ }^{4}$ Finally, "Flat Tax" proposals derived from the work of Robert Hall and Alvin Rabushka may best be viewed as a VAT in which taxes on the wage base are collected at the household level, while taxes on the remainder of value added remain collected at the firm level. ${ }^{5}$ 
Numerical analysis of any given proposal requires that we choose among these alternatives, but that we transform the model in three ways. First, we must choose specific functional forms for our demand-side and supply-side relationships. Next, we must adopt specific values for the parameters for our functions and for both the current system and proposed tax systems. Finally, we must solve the non-linear, simultaneous equations that characterize the evolution of housing market prices and quantities.

\subsection{Solution Method}

We solve the model in three steps. First, we work with a version of the model in which the variables of interest (e.g., housing prices and quantities) are entered as logarithms. This moves the center of attention away from overall levels in favor of logarithmic changes; i.e., percentage changes. Next, we linearize (in logs) the model in the vicinity of the post-reform steady-state values and compute our simulations using this linearized version. Finally, we impose upon our solutions perfect foresight. Specifically, using an iterative search, we calculate the initial decline or jump in asset prices such that the entire subsequent sequence of asset price changes leads precisely to the post-reform steady state.

\subsection{Functional Forms and Parameter Values}

The basic parameters are shown in Panel $\mathrm{A}$ of Table 1. We assume that the representative homeowner faces a property tax at a rate of 1.4 percent and that maintenance and depreciation average 3.0 percent of the house value. Also, we assume that the service flow and housing stock are linked by the constant elasticity function

$$
S=S_{o} H^{\eta}
$$


where $S_{o}$ is a constant and $\eta<0$ is the inverse price elasticity of demand. Our settings for the parameters of the function are also shown in the table. For our baseline simulations, we choose the (inverse price) elasticity of demand for housing services to be $\eta=-2.0$, but we vary this value between -0.5 and -3.0 to gauge the impact of this parameter on the simulations. On the supply side, we use a baseline elasticity of construction with respect to $Q_{H}(\epsilon)$ of 0.8 . Again, however, because the responsiveness of new construction to the alterations in the tax regime are central to the dynamics of the housing market we vary this elasticity between 0.1 and $0.9 .^{6}$

We model two reforms: (1) a partial reform, eliminating the deductibility of mortgage interest and property taxes, and (2) the variant of the Flat Tax proposed by Congressman Armey and Senator Shelby. For purposes of comparison, we follow closely the choices of CGH in choosing our numerical parameter values for these reforms, which are shown in Panel B of Table 1.

We set the nominal, pre-tax interest rate at 7.5 percent and assume that it is unaffected by the tax reform. There is considerable debate regarding the impact of tax reform on interest rates; our goal is to focus on the act of reform itself and abstract from ancillary economic impacts. ${ }^{7}$ Note that, ceteris paribus, this choice likely serves to maximize the negative impacts of tax reform, because any reduction in interest rates would serve to raise housing values. Following $\mathrm{CGH}$, we set the average marginal tax rate in the current system at 0.22 . When simulating the effects of removing deductibility in a revenue-neutral framework, we again follow their guidance and employ a rate of 0.194 . We set the tax rate for the Flat Tax at $0.17 .^{8}$

As noted in CGH, roughly 40 percent of homeowners do not itemize; we set the fraction of mortgage interest and property tax deductible equal to 0.60 . Under each of the reforms mortgage interest is not deductible, so we set $\theta=0$. Similarly, property taxes lose their deductible status under both of the reforms examined. 
The next two rows of the table show the financing and construction cost of housing, respectively. To focus on the real valuation of assets, we fix the loan-to-value (LTV) ratio ( $\beta$, above) at 0.4 throughout. ${ }^{9}$ We assume that the (normalized) replacement cost of a unit of housing is exogenously set at 1.0. Under the Flat Tax the business-level tax (at a rate of 17 percent) raises the tax-inclusive break-even replacement cost correspondingly. The final row of Table 1 shows a parameter that indicates the degree to which capital income is subject to tax. We choose a pre-reform value of $e=0.5$, a choice based on Engen and Gale [1996] that reflects the widespread existence of tax-preferred saving vehicles that permit substantial amounts of interest (and other capital income) to escape income taxation. Because capital income taxation is eliminated by the Flat Tax, $e$ falls to $e=0.0$.

\section{SIMULATION RESULTS}

We turn now to the results of simulating the reforms. The simulations provide two types of responses: changes in the steady-state in the housing market and the dynamics of adjustment between the original and new steady states. Although not the primary focus of this study, we begin with the former before turning to an analysis of the adjustment paths.

\subsection{Tax Reform and Steady-State Responses}

Our examination of steady-state responses begins in Table $2 .{ }^{10}$ As shown, the steady state changes in the value of $Q_{H}$ are dictated directly by the tax regime. Under the Flat Tax the steady-state value of $Q_{H}$ rises by a percentage amount equal to the business-level tax on new construction. Simply removing deductibility has no effect on $Q_{H}$.

In contrast, the contraction in the quantity of housing stock differs markedly across the alternative reforms. Consider the first row of the table, which shows the results of our baseline 
simulation. Under these assumptions, removing the deductibility of mortgage interest and property taxes induces a steady state decline of 1.9 percent in the housing stock. By contrast, the Flat Tax results in a greater steady-state decline of 8 percent in the quantity of owner-occupied housing. In short, removing the tax-subsidy to owner-occupied housing and/or taxing it leads to a smaller housing stock, an unsurprising qualitative result.

These steady-states are constructed under the partial equilibrium assumption that the long-run supply of housing is perfectly elastic at a constant replacement cost, so changes in the parameters of the construction function do not affect these simulations. Changes in the parameterization of housing demand, however, do influence the nature of the steady state. In particular, the rows of the table show the effect of varying the value of $\eta$. Looking across columns, varying the service-flow-to-stock relationship does not alter the ordering of the housing stock impacts of the reforms. Glancing down rows, however, indicates that the parameter is crucial for determining the real impacts of tax reform. As the absolute value of the elasticity of the demand for housing (with respect to the rental rate) falls (i.e., as $\eta$ grows in absolute value), the smaller the decline in the stock of housing. Not surprisingly, the more elastic is demand, the greater the impact of introducing a tax.

\subsection{Tax Reform and Dynamic Adjustment}

At the heart of our model is the specification of housing market dynamics. Consider Figure 4, which shows the impact of removing the deductibility of mortgage interest and property taxes. As shown, the immediate effect is a reduction in housing values, an impact consistent with the theoretical prediction in Figure 3. However, the magnitude of the decline is only a bit more than one percentage point and is quickly reversed. 
By comparison to removing deductibility, the Flat Tax is a much more fundamental reform. However, our simulation of the effects of the Flat Tax (Figure 5) does not suggest a dramatic decline in housing values. Instead, the short-run impact is for prices to rise by roughly 10 percent and ultimately by 17 percent. $^{11}$ This is the response precisely suggested by Figure 2 . Thus, the decline due to the loss of deductibility is more than offset by the positive impact on prices of the business-level tax.

Not surprisingly, the supply elasticity is important to the process of dynamic adjustment. To gain a feel for the impact, we re-computed our simulated reforms using a much lower value of the supply elasticity, $\epsilon$, of 0.3 instead of 0.8 . Comparing Figure 6 with Figure 4 indicates that the lowered responsiveness generates a larger initial decline and a slower convergence to the new long-run equilibrium. However, the main message of Figure 6 appears to be that, for plausible parameter values, the housing market implications of removing deductibility are quite modest. A similar lesson emerges from comparing Figures 5 and 7. Again, a less responsive construction industry leads to stronger downward pressure on prices - in this case a smaller rise-and slower adjustment to the steady state.

To summarize, under our assumptions the long-run impact of tax reform on housing prices appears to be minimal. The key is our view that, despite its large absolute size, the housing market is best thought of as a price-taker with respect to the remainder of the economy. Hence, long-run prices are best thought of as driven by highly elastic supply conditions. Of course, housing quantities will be responsive to reform. Those reforms that reduce the taxsubsidy to housing and raise the effective price, will lower the demand for housing.

The more important impacts concern the transition to the steady state. In a model designed to highlight these transitional issues we find that, for plausible parameter values, the likely impact of tax reform on the housing market is quite modest. 


\section{5. $\quad$ ROBUSTNESS CHECKS}

Our results stand in sharp contrast to fears of a housing market crash in response to tax reform. Why? One possibility is that carefully modeling the transitional dynamics generates the "right" answer; our model is constructed especially to capture such effects. Of course, one might wonder if the model is capable of producing adverse effects on the housing market at all. Even if so, the possibility remains that our model is too stylized to capture important dynamics. In this section, we address each issue in turn. First, we construct "worst case scenarios" that maximize the short-run impact on housing prices. Next, we examine the sensitivity of the dynamic structure to the introduction of a relatively slowly adjusting residential land market into our simulations.

\subsection{Worst-Case Scenarios for Tax Reform}

Figures 8 and 9 show the short-run impacts and dynamic adjustments to tax reform under "worst-case" conditions. Specifically, we assume that all homeowners itemize their deductions and that each home is fully mortgaged (i.e., the loan-to-value ratio is 1.0 ), thereby maximizing. the impact of the loss of deductible mortgage interest. Moreover, we focus the analysis on the homes of the well-to-do by assuming that all households have a marginal tax rate of 39.6 percent. Similarly, we assume that the supply response $(\epsilon)$ is a minimal 0.1 and that $\eta$ is -0.5 . The combined effect of these choices is that housing prices are forecast to fall by roughly 18 percent in response to the loss of deductibility (see Figure 8 ) and to recover only very slowly. Similarly (see Figure 9), in these circumstances the move to a Flat Tax results in a decline of 12 percent in housing prices, in contrast to the upward pressures found before. One interpretation of these results is that while the aggregate housing market would be relatively unaffected, one might expect particular market segments to show a greater response to tax reform. 


\subsection{The Role of Land in Housing}

The discussion thus far has treated housing as a reproducible capital good available at an exogenously set long-run price (normalized to the replacement cost of 1.0). At the other extreme, one might argue that the essence of housing is residential land that is fixed in supply. Thus, one should treat the quantity of housing as exogenous, and permit the long-run price to adjust. In practice, both capital and land are embodied in housing units and neither is perfectly inelastic in supply. Hence, following Poterba [1984], we expand the model to incorporate the use of both land and capital in the production of housing units.

Specifically, we assume a Cobb-Douglas function for the production of housing $H$

$$
H=K^{\alpha} L^{1-\alpha}
$$

where $K$ is housing structures and $L$ is land. In analogy to the discussion above, the supply of capital and land to the housing sector is determined by the valuation of these factors relative to their (exogenous) replacement cost. Specifically, if $\epsilon_{\mathrm{K}}$ and $\epsilon_{\mathrm{L}}$ are supply elasticities:

$$
\begin{aligned}
& \dot{K}=\phi\left(Q_{K}\right) K=Q_{K}^{\epsilon_{K}} K, \text { and } \\
& \dot{L}=\psi\left(Q_{L}\right) L=Q_{L}^{\epsilon_{L}} L .
\end{aligned}
$$

Thus, the specification permits differential speeds of adjustment for the capital market and the land market.

To parameterize the model, we assume that $\alpha$ is equal to 0.85 , that $\epsilon_{\mathrm{K}}$ is 0.8 , and $\epsilon_{\mathrm{L}}$ is 0.2 . The latter two assumptions are intended to capture the relatively slow adjustment of the land market compared with the market for capital goods. The implications of these assumptions are apparent in Figure 10, which displays the impact of removing deductibility on factor usage in the residential housing market. As the figure shows, the quantity of capital inputs reaches the steady state value relatively quickly, while the use of land inputs adjusts much more slowly. 
Interestingly, the initial impact of the tax reform is to raise the usage of land, a feature that may be traced to the factor price movements depicted in Figure 11. In the aftermath of the tax reform, the asset price of land falls relatively more ( 1.9 percent versus 1.2 percent) than that for capital. Ceteris paribus producers shift to a more land-intensive mix of factor usage.

Eventually, however, the overall contraction of the housing sector leads to less demand for both capital and land.

As before, however, the overall magnitudes of the shifts in prices and inputs are relatively modest, under 2 percent. The overall impacts are collected in Figure 12, which shows the time path of the adjustment of the composite good "housing" and its price. Even with the inclusion of a more realistic specification of the production structure, this particular (partial) reform does not generate a large dislocation in the housing market.

Does this pattern hold for the Flat Tax reform as well? The results of these simulations are depicted in Figures 13 through 15. Beginning with the latter, one finds that the two-factor housing model generates the same overall implications as those from our more parsimonious specification. Turning to the former figures, one sees that the Flat Tax generates the same shortrun incentives to shift the mix of factor usage toward land and away from capital (Figure 13). ${ }^{12}$ And, as captured by Figure 14, the Flat Tax places upward pressure on the prices paid by producers of new housing. ${ }^{13}$

\section{CONCLUSIONS}

Using a carefully specified simulation model crafted to integrate the short-run and longterm impacts of tax reform on the housing market, we find modest impacts from even fundamental reform of the Federal income tax. These results suggest that concerns over the impact of tax reform on housing values and household net worth may be overstated and, to the 
extent that reform is otherwise desirable, should not stand as an impediment to reform. Our results stand in contrast to other analysts' predictions of dramatic impacts on the housing market. The difference may be traced to a modeling strategy that embodies forward-looking household behavior in the demand for housing services and housing assets.

Of course, our analysis comes with several caveats. As with any simulation study, the results are dictated by the parameter values chosen; improved empirical guidance regarding some of the key parameters would be a valuable avenue for future research. In particular, much remains to be learned regarding the relationship between new construction and the valuation of existing houses. Second, our aggregate model is not capable of delineating important distributional effects; whether these effects be computed across individuals, across density of housing (urban versus suburban), or across regions. Finally, the model is partial equilibrium. While this permits one to focus on owner-occupied housing, it precludes understanding fully the implications of the relationships between the market for owner-occupied housing, rental housing, and the economy as a whole. 
1. DRI estimates the value of the mortgage interest ( $\$ 62$ billion) and property tax ( $\$ 22$ billion) deductions to be $\$ 84$ billion annually. Using a real discount rate of 0.05 , the value of this in perpetuity is $\$ 1.7$ trillion.

2. The magnitude of the jump from $A$ to $B$ depends upon the size of the change in the steady state values and the speed of adjustment as determined by equation (2.4).

3. In equilibrium, the purchase price of the house is equal to the present value of the future consumption stream. Hence a tax on the purchase price is equivalent to "prepaying" a stream of future taxes on the annual consumption value.

4. The equivalence between the retail sales tax and the VAT is perhaps most easily seen by viewing the VAT as a multi-stage collection mechanism for the tax on the final product.

5. Another possibility is a "consumed income tax" administered entirely at the household level, however political realities appear to preclude this approach. Thus, for example, we do not address the USA tax of Senators Nunn and Domenici.

6. Many observers feel that housing market supply responses are asymmetric-increases are more elastic than contractions in supply. Our simulations focus exclusively on scenarios that result in a decline in the stock of housing, and our elasticities are best interpreted in this context.

7. See Hall and Rabushka [1995] for a discussion suggesting a decline in interest rates. Feldstein [1995] argues that reform would not lower, and might even raise, interest rates.

8. The long run tax rate is 0.17 in the Armey-Shelby bill, although a higher tax rate prevails during a transition period.

9. Households will also respond to tax reforms by altering the financing of their homes (see Follain and Sturman [1997]). Of course, in doing so, they will choose the financing mix that is most advantageous, thereby serving to minimize the impact on housing prices. In this way, our assumptions allow us to provide an upper bound to the impact of tax reform.

10. The steady state values are computed by setting $\dot{Q}_{H}=0$ in equation (2.3), imposing the long-run value of $Q_{H}$, and solving for the corresponding value of $H$.

11. Note that the net-of-tax price initially declines, exactly the incentive required to induce a contraction in the supply of housing.

12. This is hardly surprising as the Flat Tax reform embodies the removal of deductibility.

13. The prices are gross of tax. Net of tax returns decline during the transition, providing the incentive to shift capital and land out of the housing sector. 


\section{References}

Brinner, Roger, Mark Lansky, and David Wyss, "Market Impacts of Flat Tax Legislation," DRI/McGraw-Hill U.S. Review, June 1995.

Capozza, Dennis R., Richard K. Green, and Patric H. Hendershott, “Taxes, Mortgage Borrowing, and Residential Land Prices," in Economic Effects of Fundamental Tax Reform, edited by Henry J. Aaron and William G. Gale, Brookings Institution Press, 1996.

Engen, Eric and William Gale, "The Effects of Fundamental Tax Reform on Saving," in Economic Effects of Fundamental Tax Reform, edited by Henry J. Aaron and William G. Gale, Brookings Institution Press, 1996.

Feldstein, Martin, "The Effect of a Consumption Tax on the Rate of Interest," National Bureau of Economic Research, Working Paper No. 5397, 1995.

Follain, James R. and Lisa Sturman, "The False Messiah of Tax Policy: What Elimination of the Home Mortgage Interest Deduction Promises and a Careful Look at What it Delivers," mimeo, Syracuse University, 1997.

Hall, Robert and Alvin Rabushka, The Flat Tax, 2nd Edition, Stanford, CA: The Hoover Institution Press, 1995.

Poterba, James, "Tax Subsidies to Owner-Occupied Housing: An Asset Market Approach," Quarterly Journal of Economics, November 1984, pp. 729-752.

Rosen, Harvey S. "Housing Subsidies: Effects on Housing Decisions, Efficiency, and Equity," Chapter 7 in The Handbook of Public Economics, Volume I, M. Feldstein and A. Auerbach (eds.), Amsterdam: North-Holland Publishing Co., 1985.

Summers, L. "The Asset Price Approach to the Analysis of Capital Income Taxation," Proceedings of the National Tax Association, 1983, pp. 112-120. 

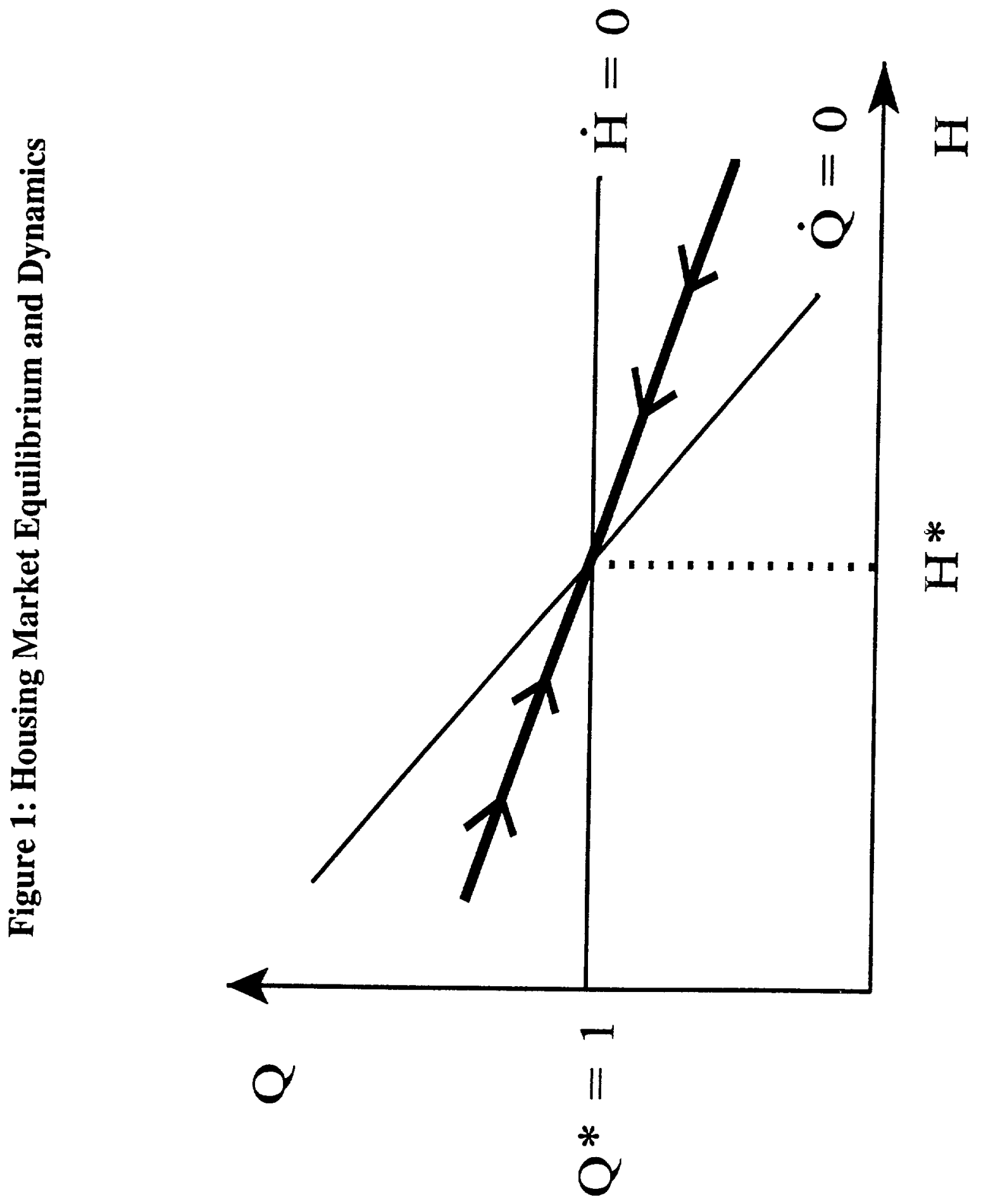


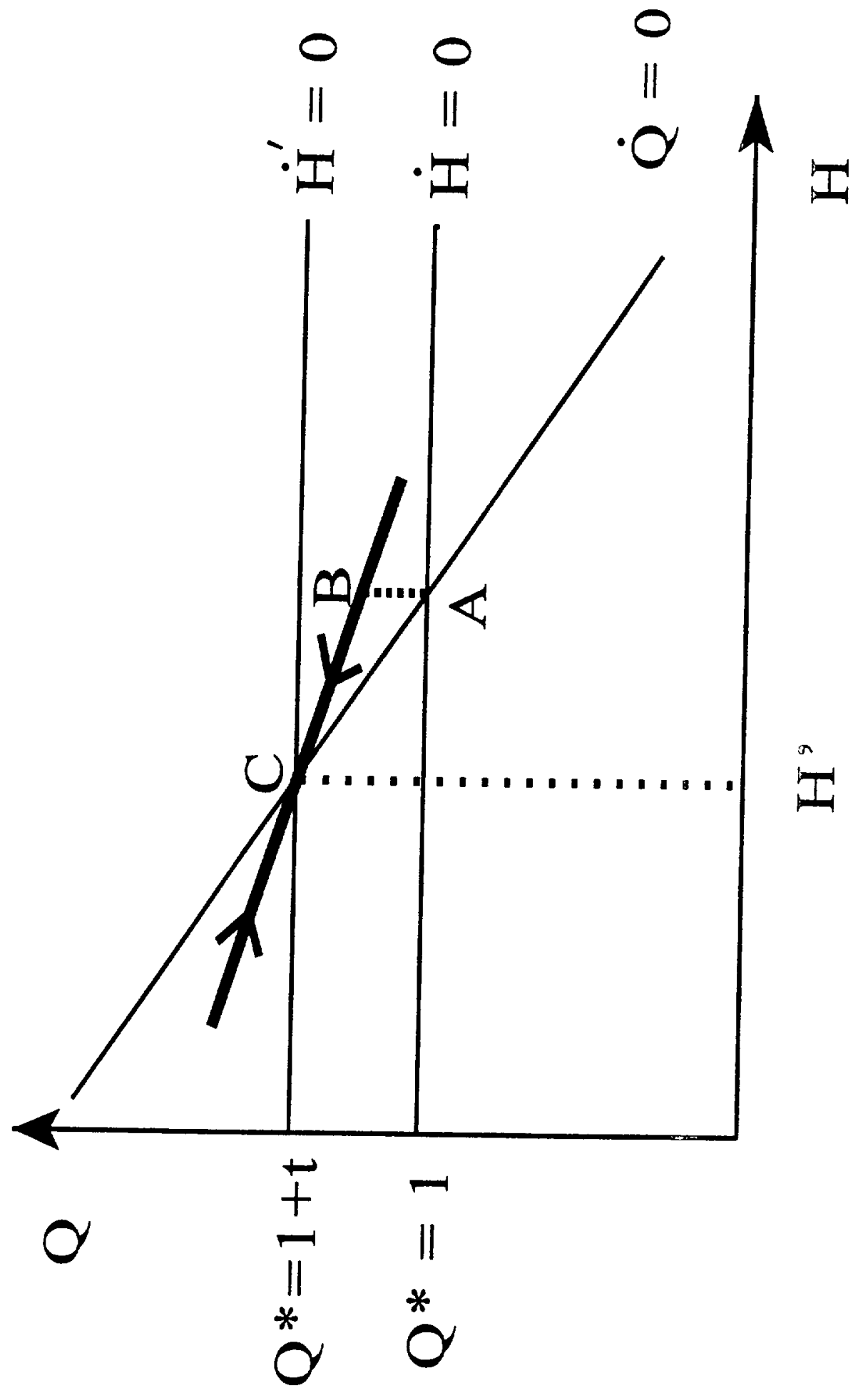




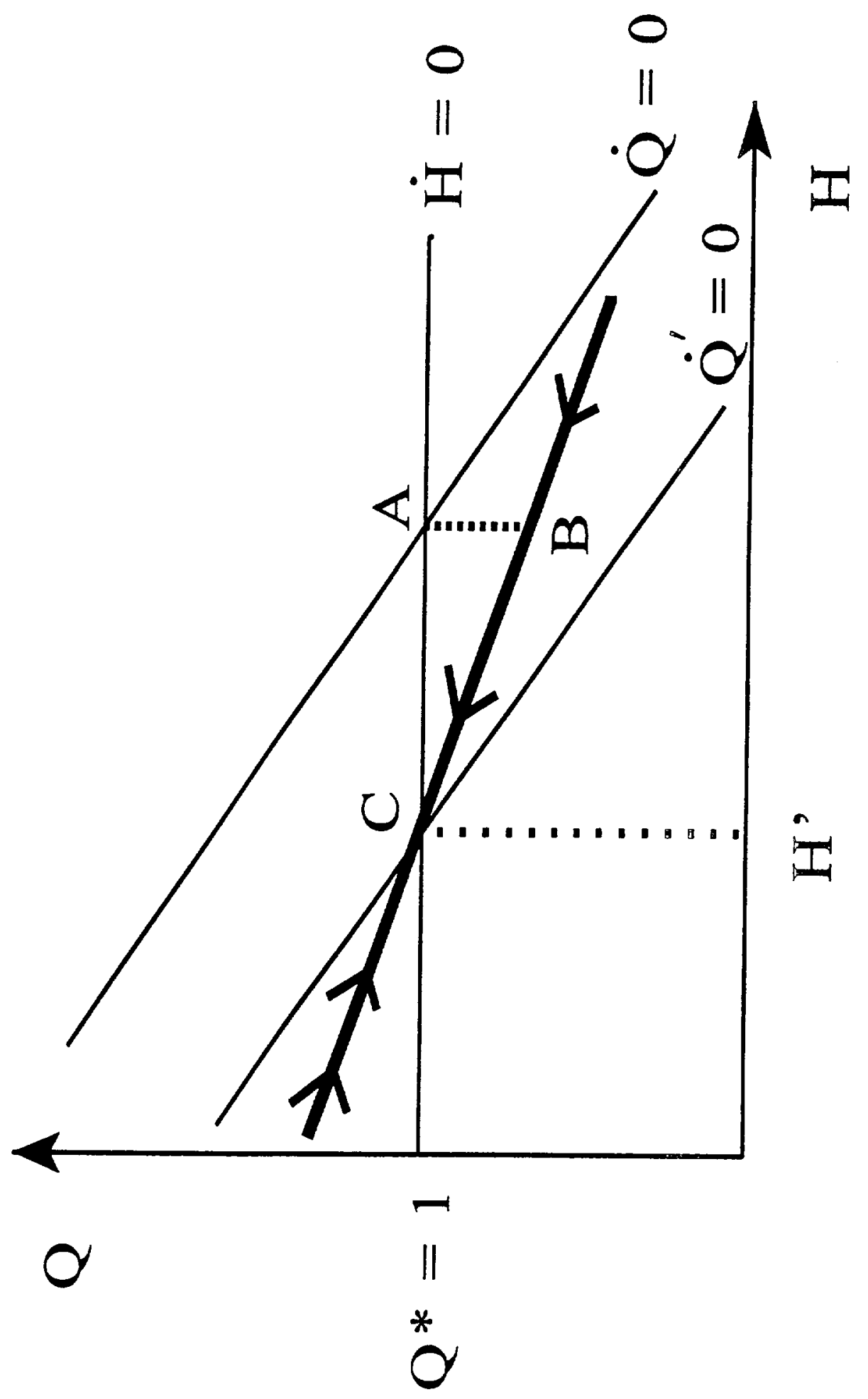




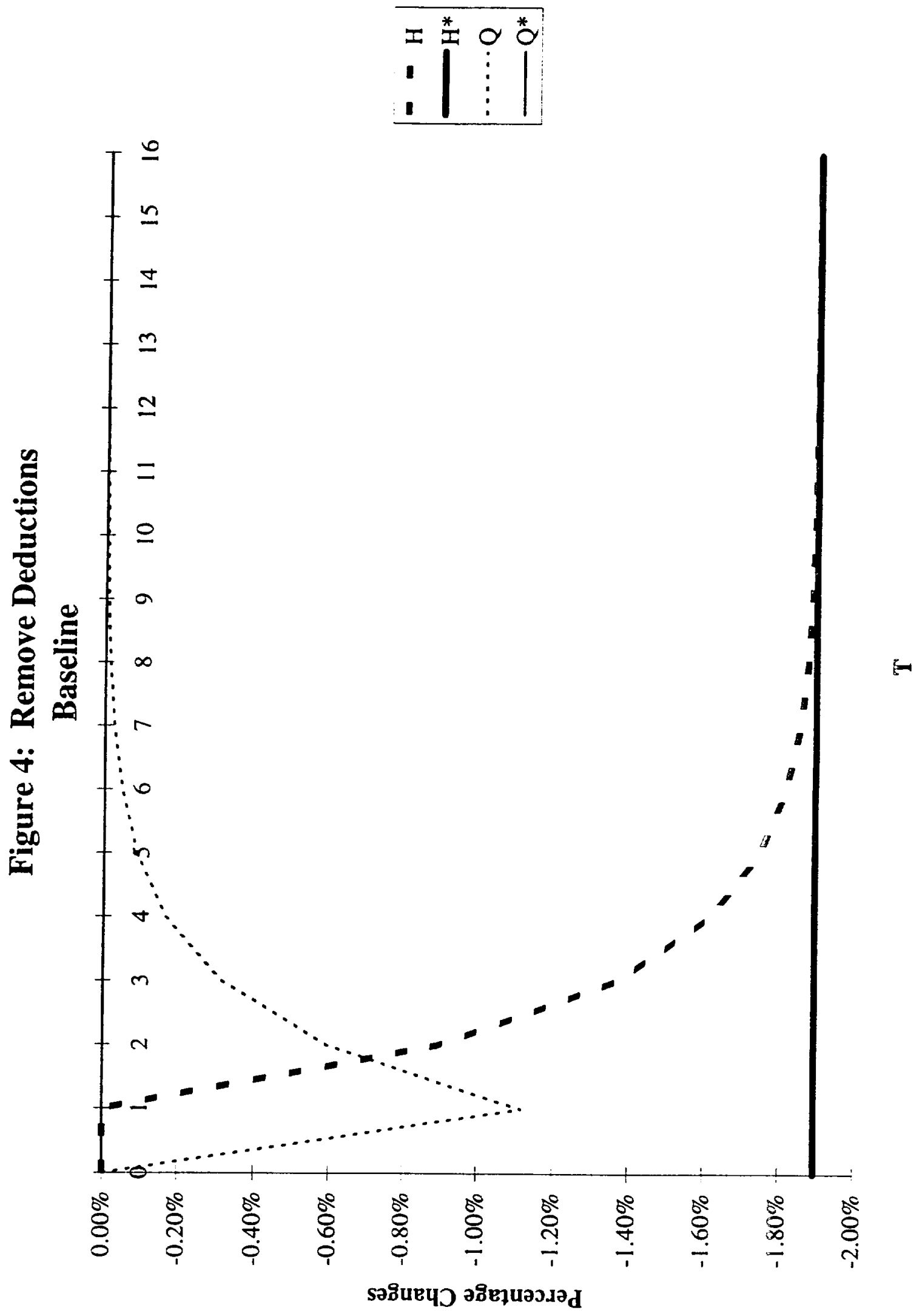




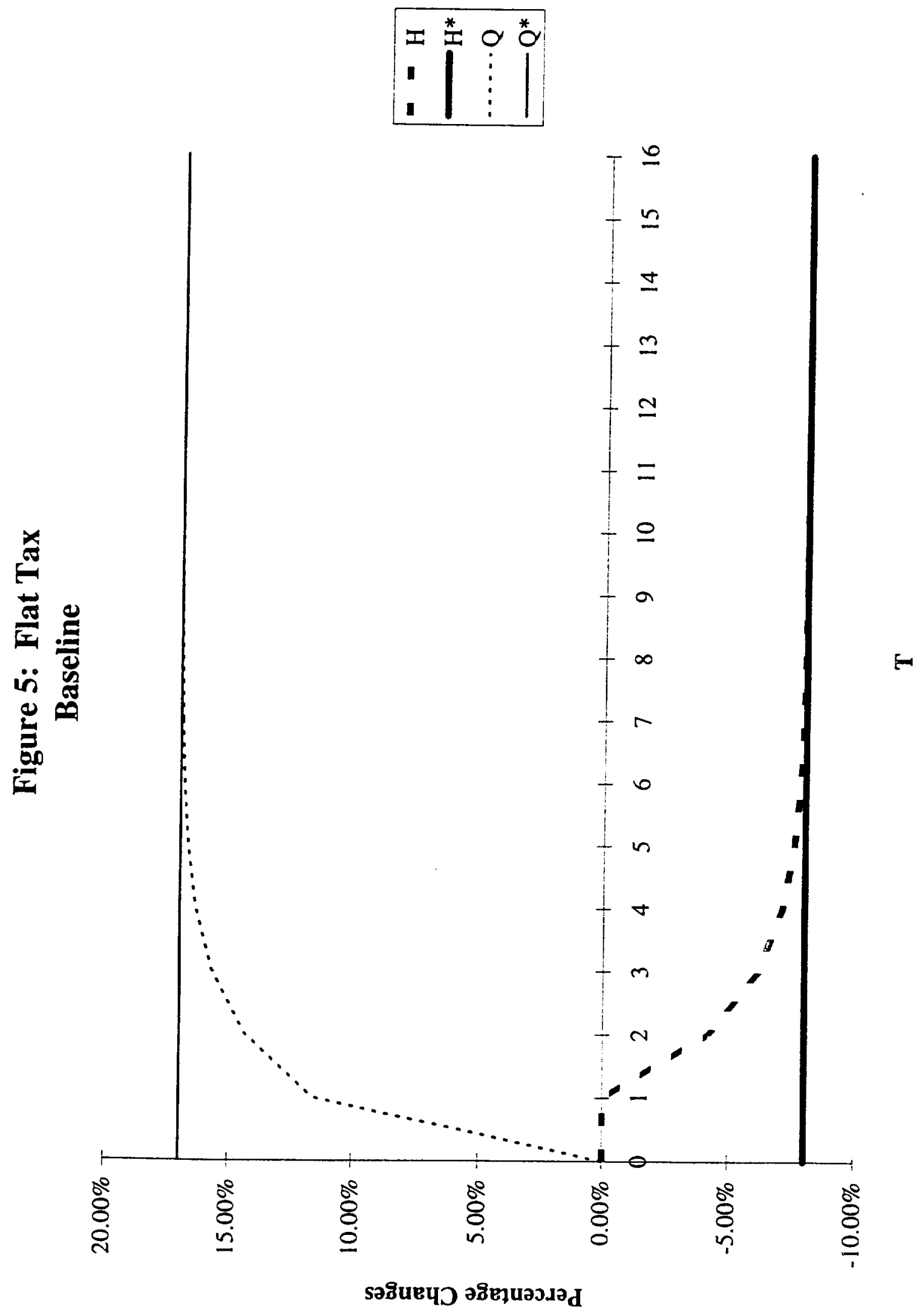




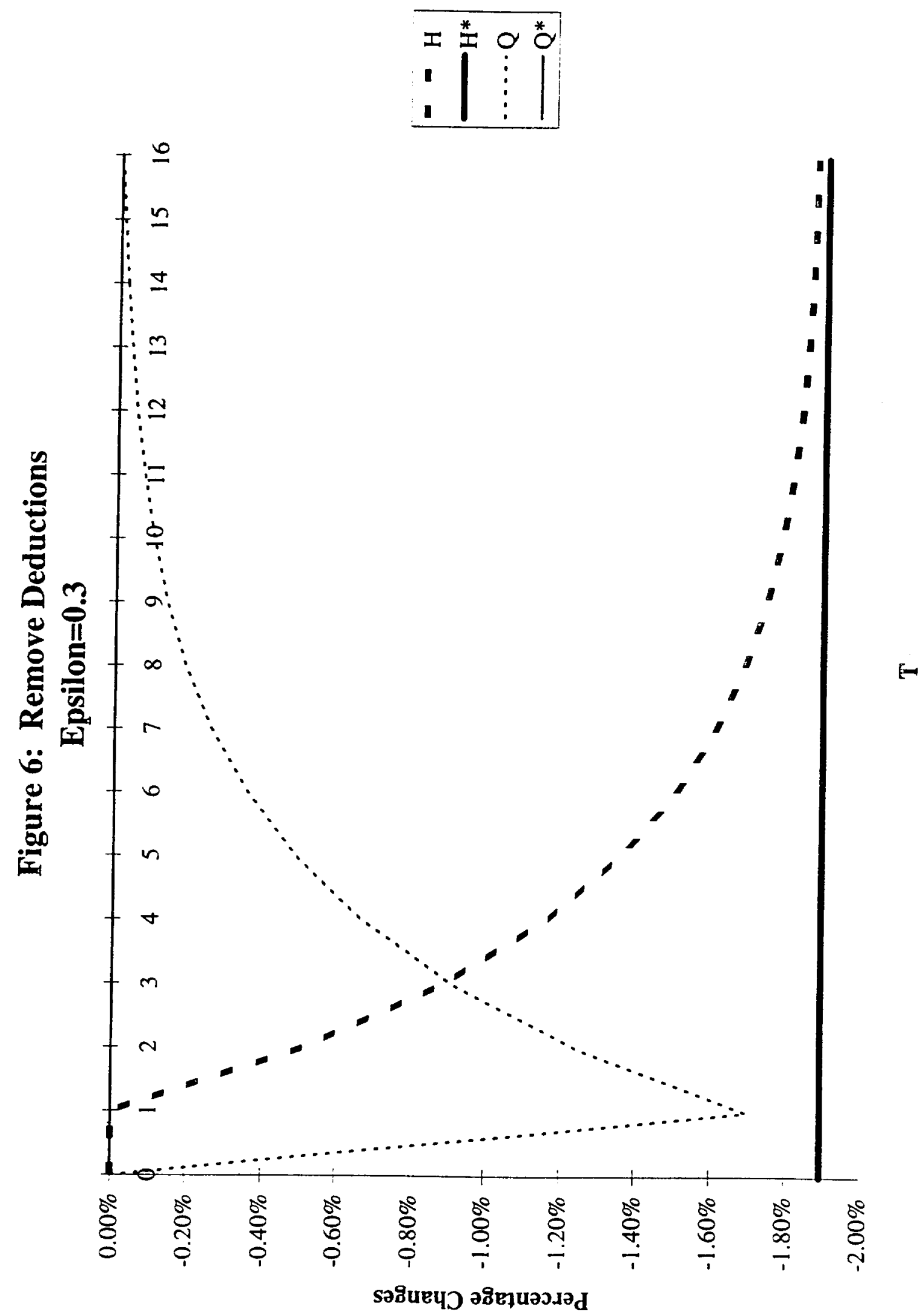




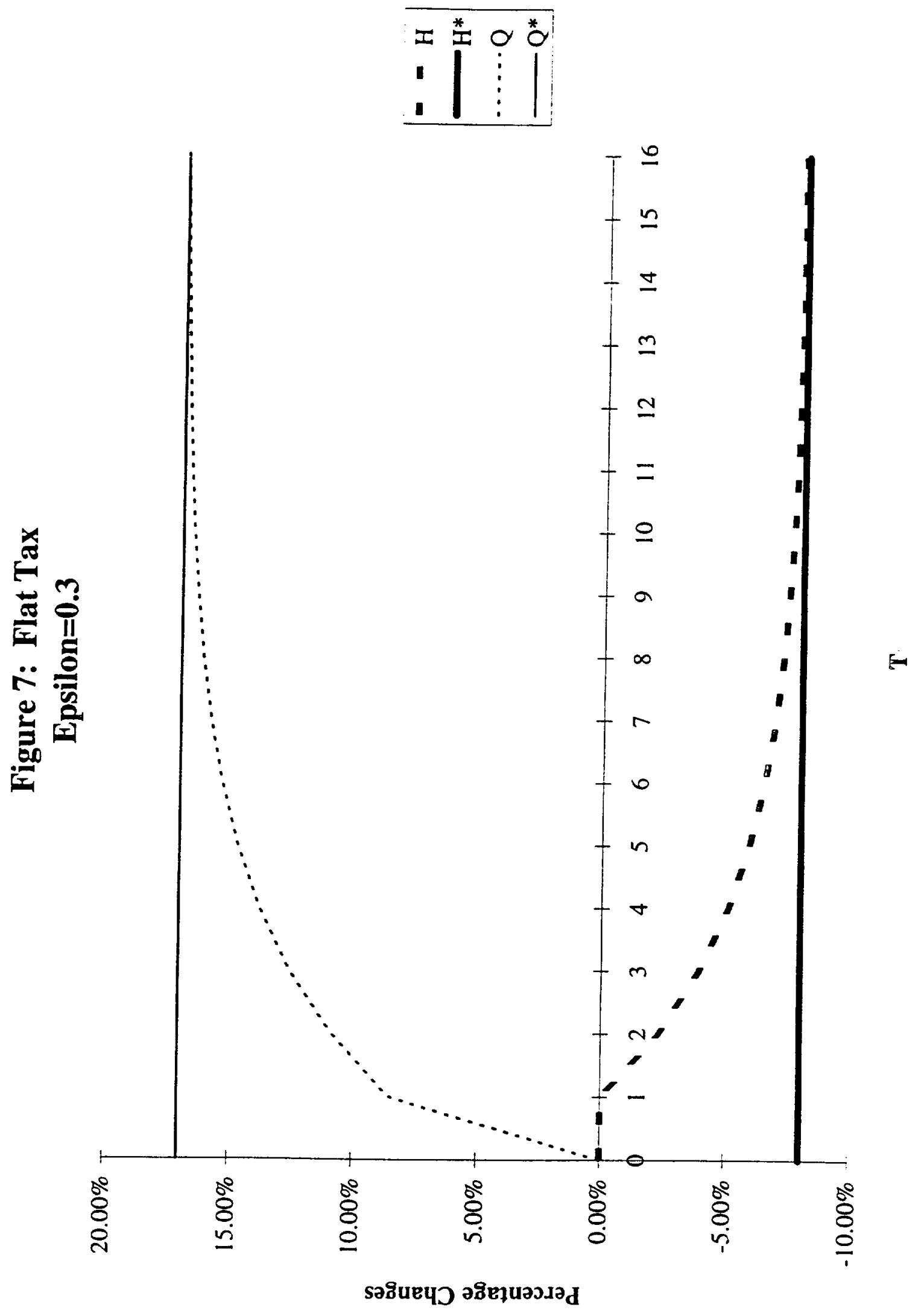




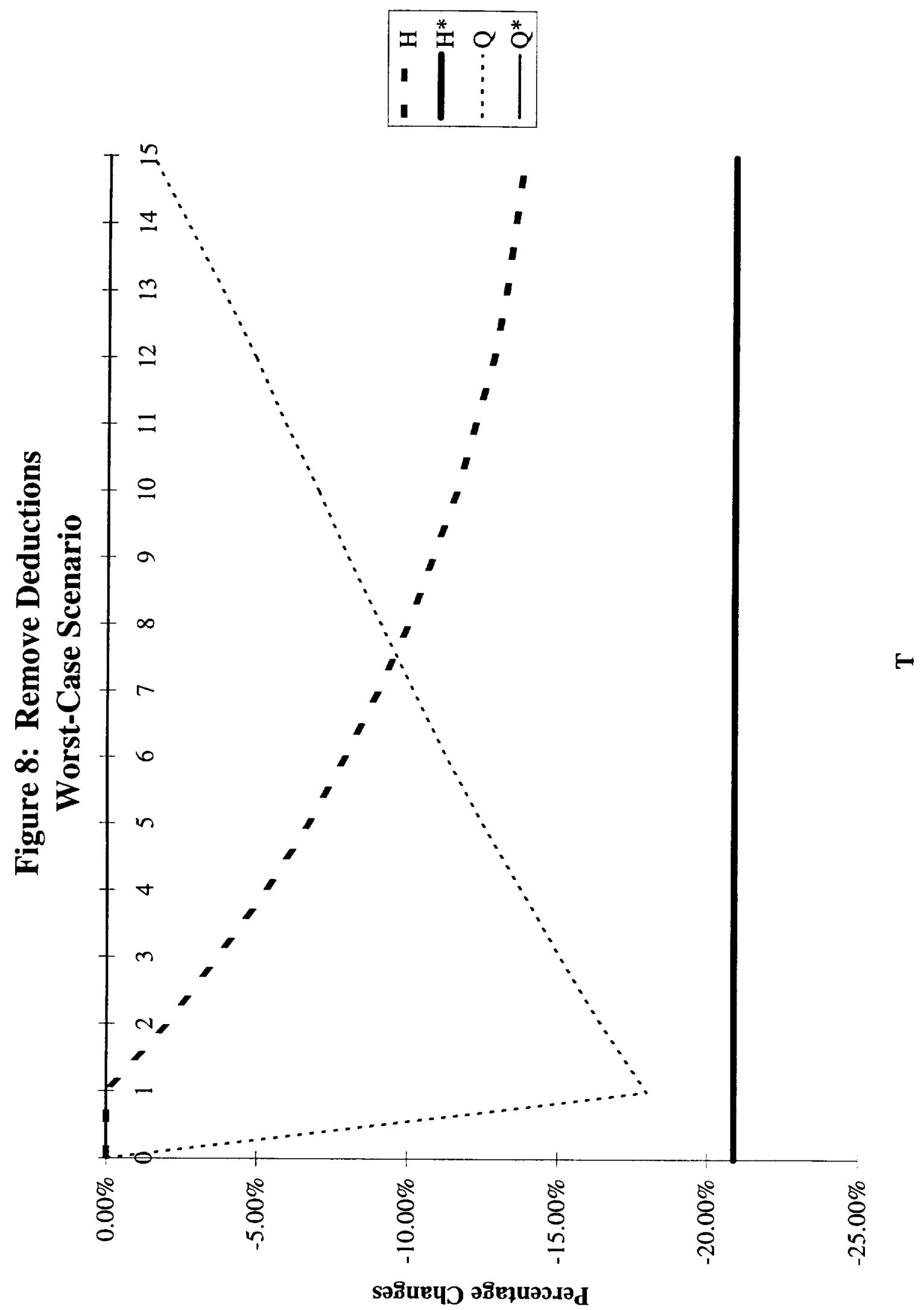




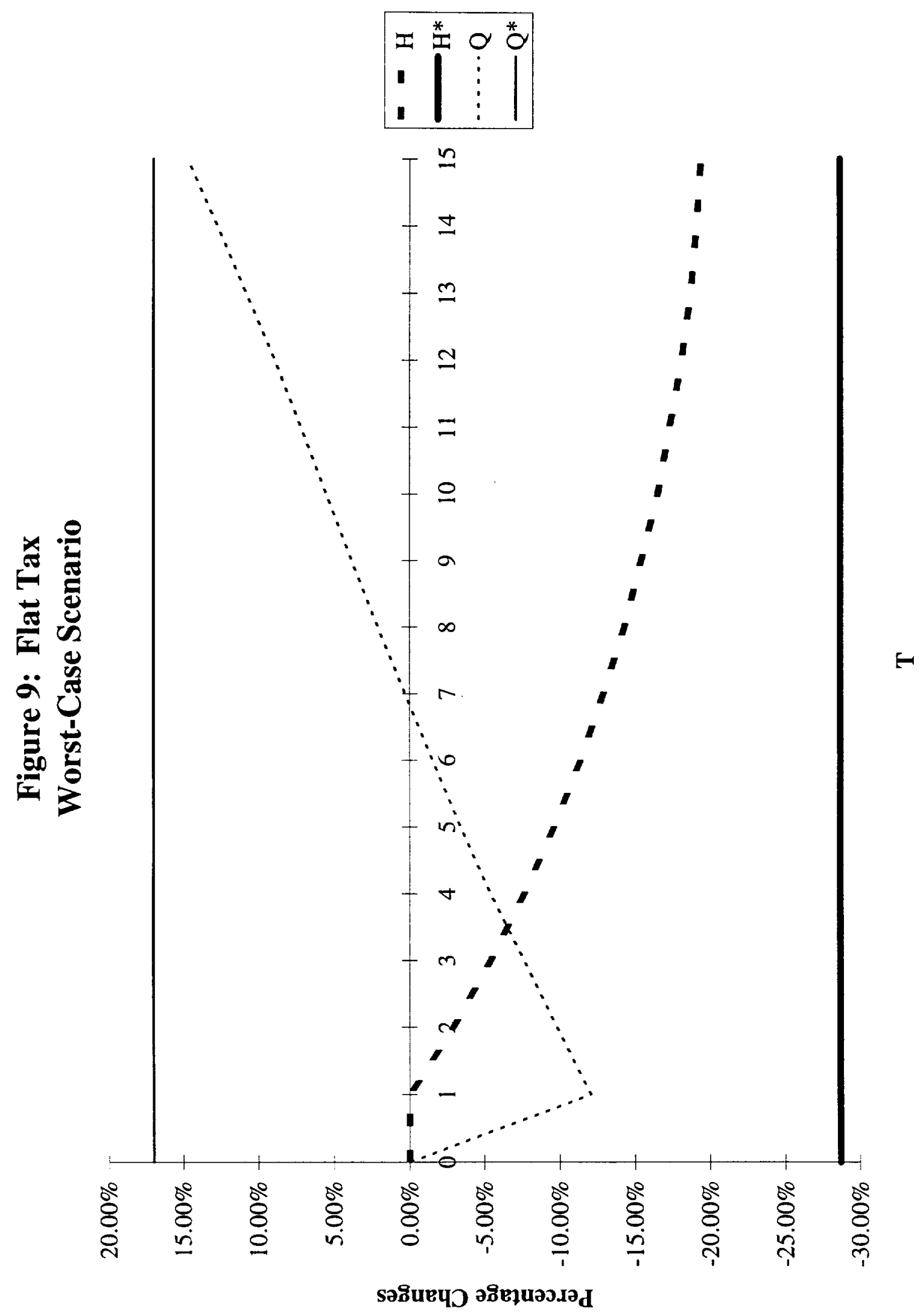



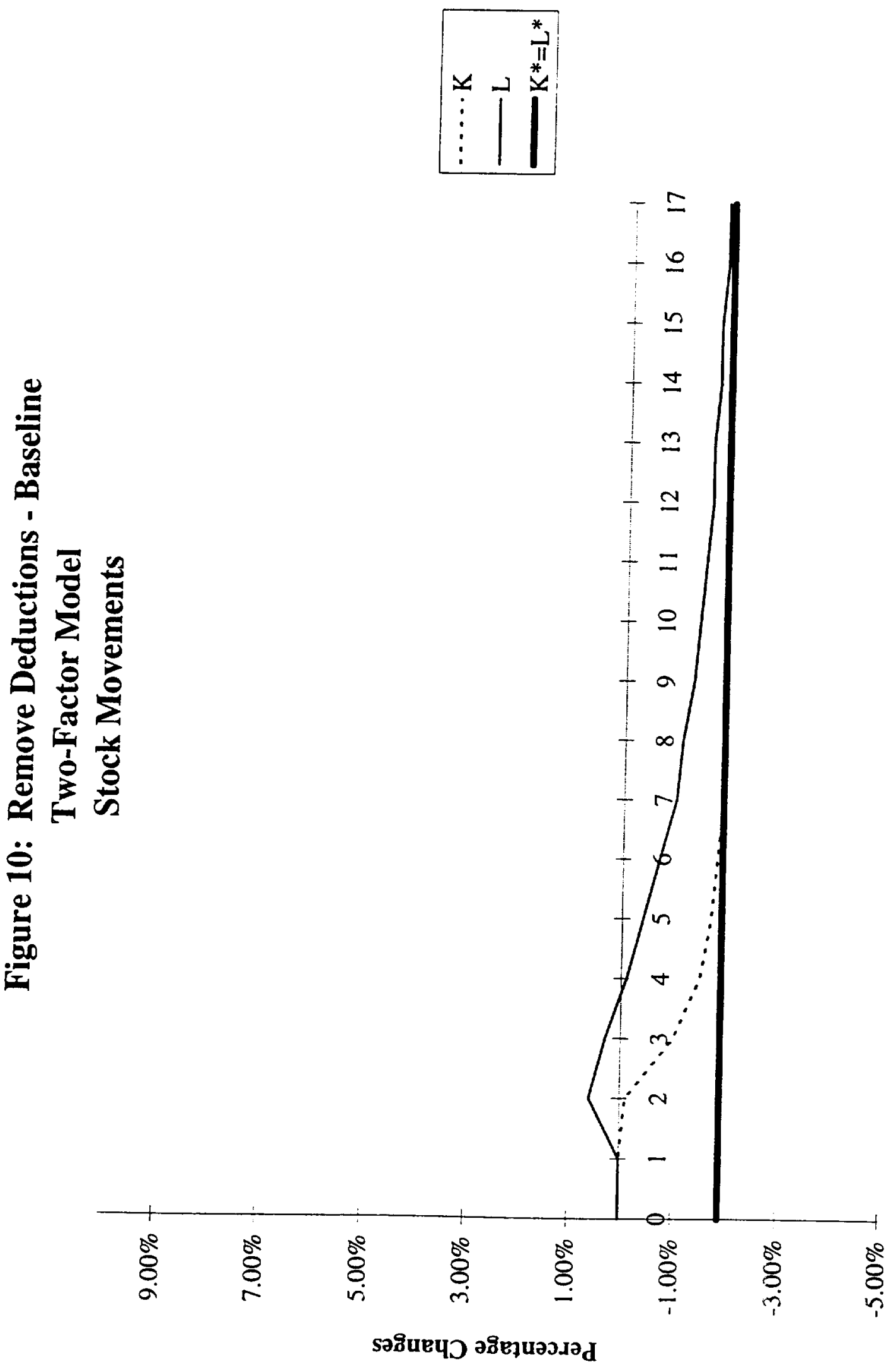

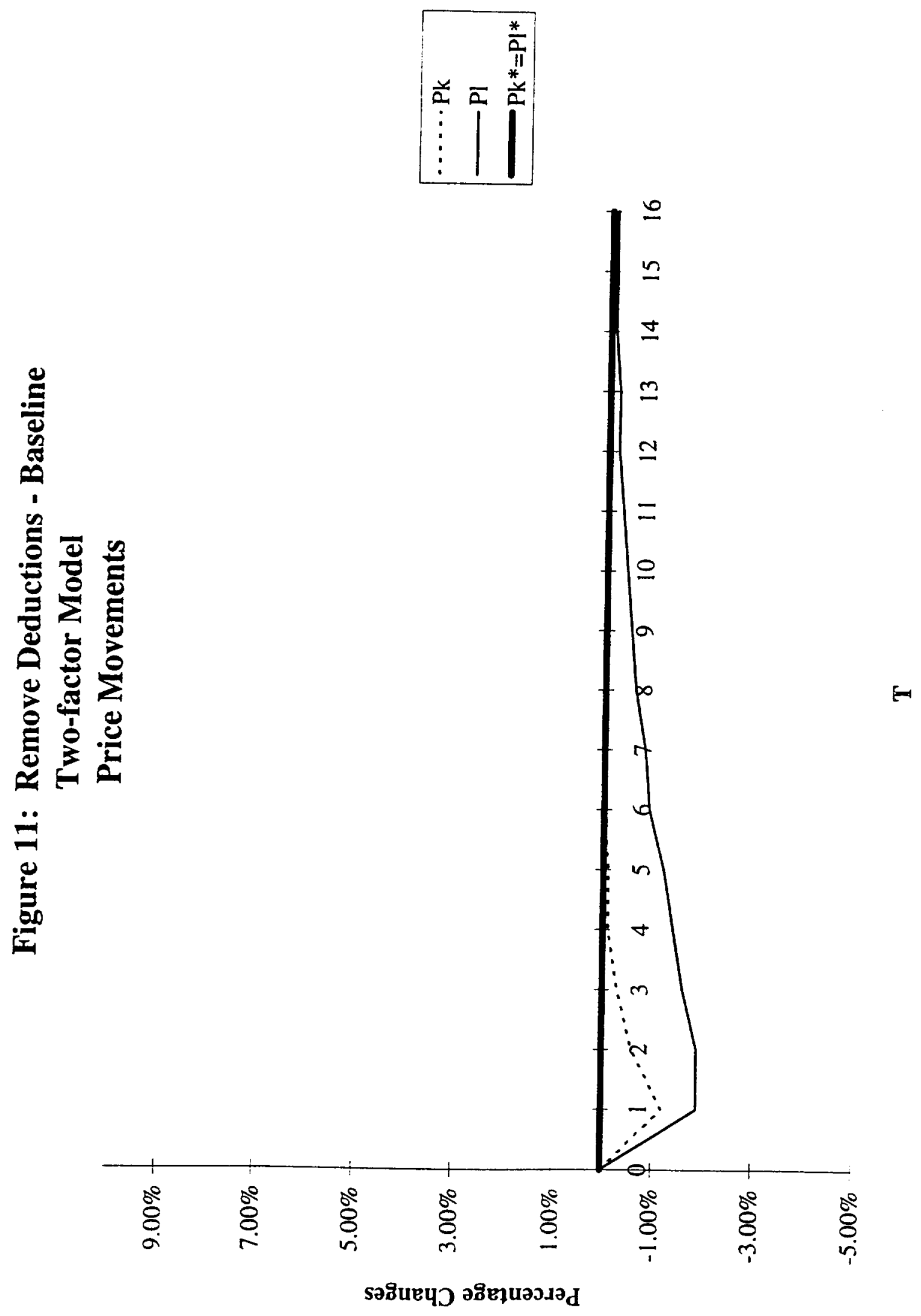

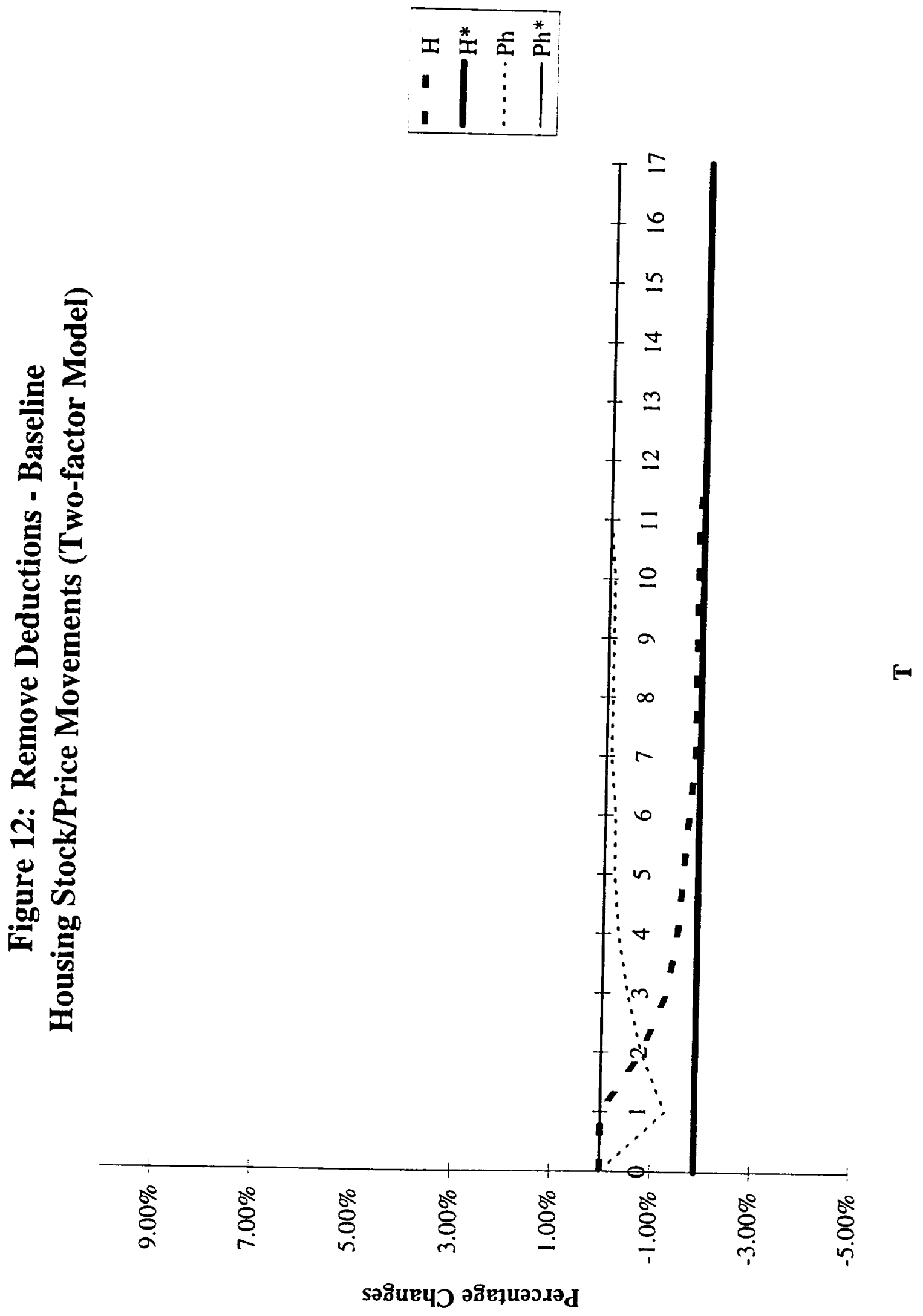


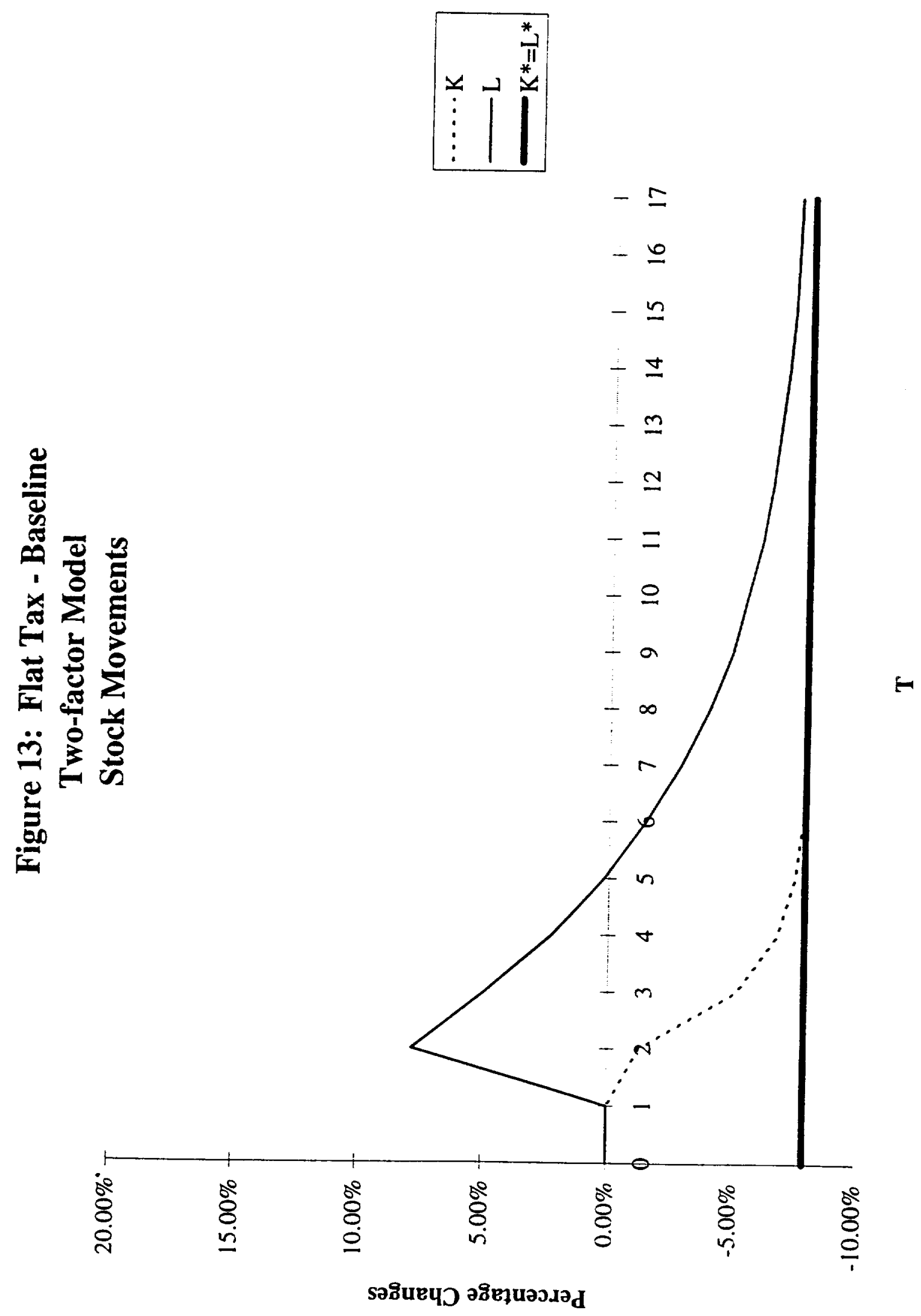




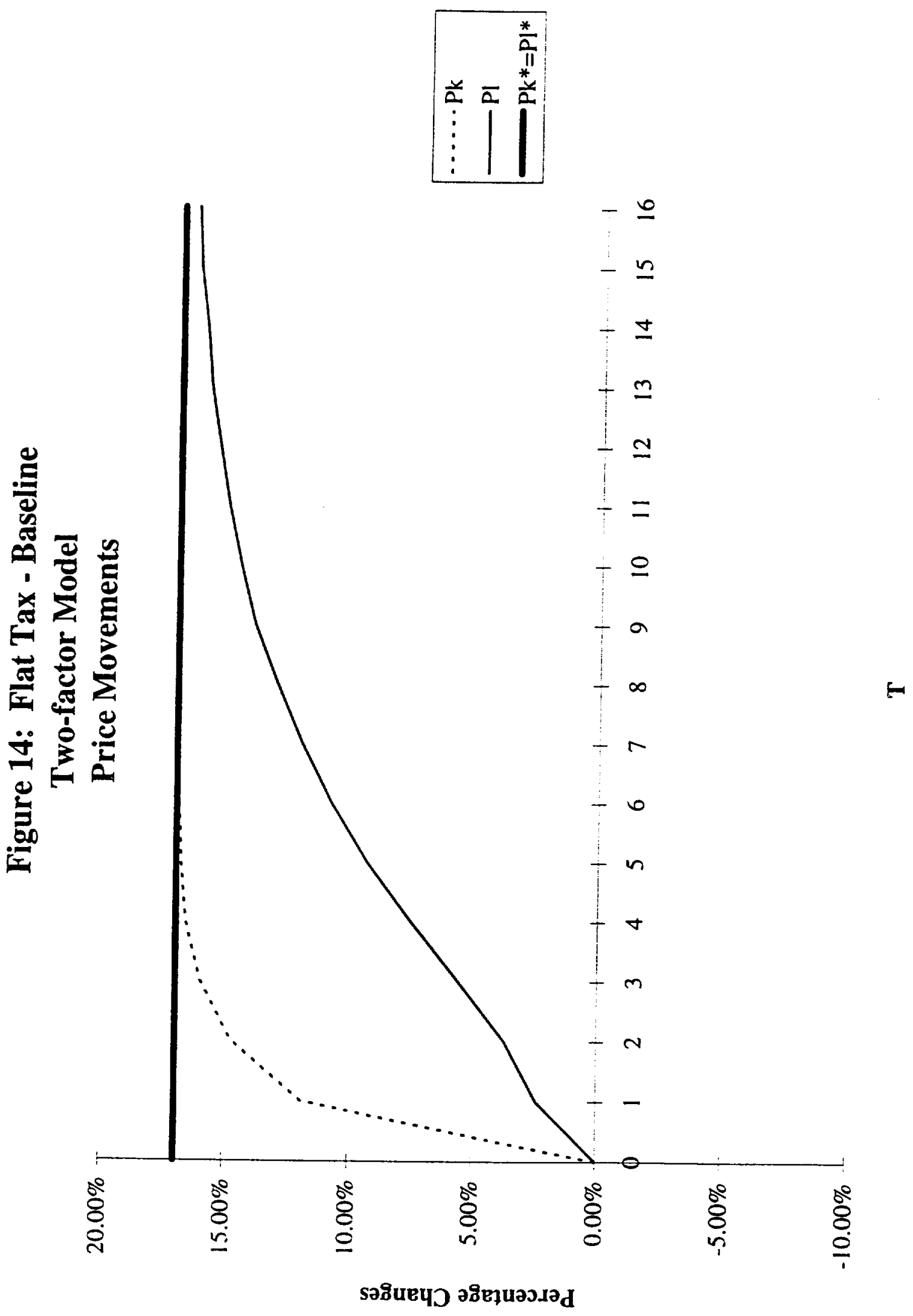



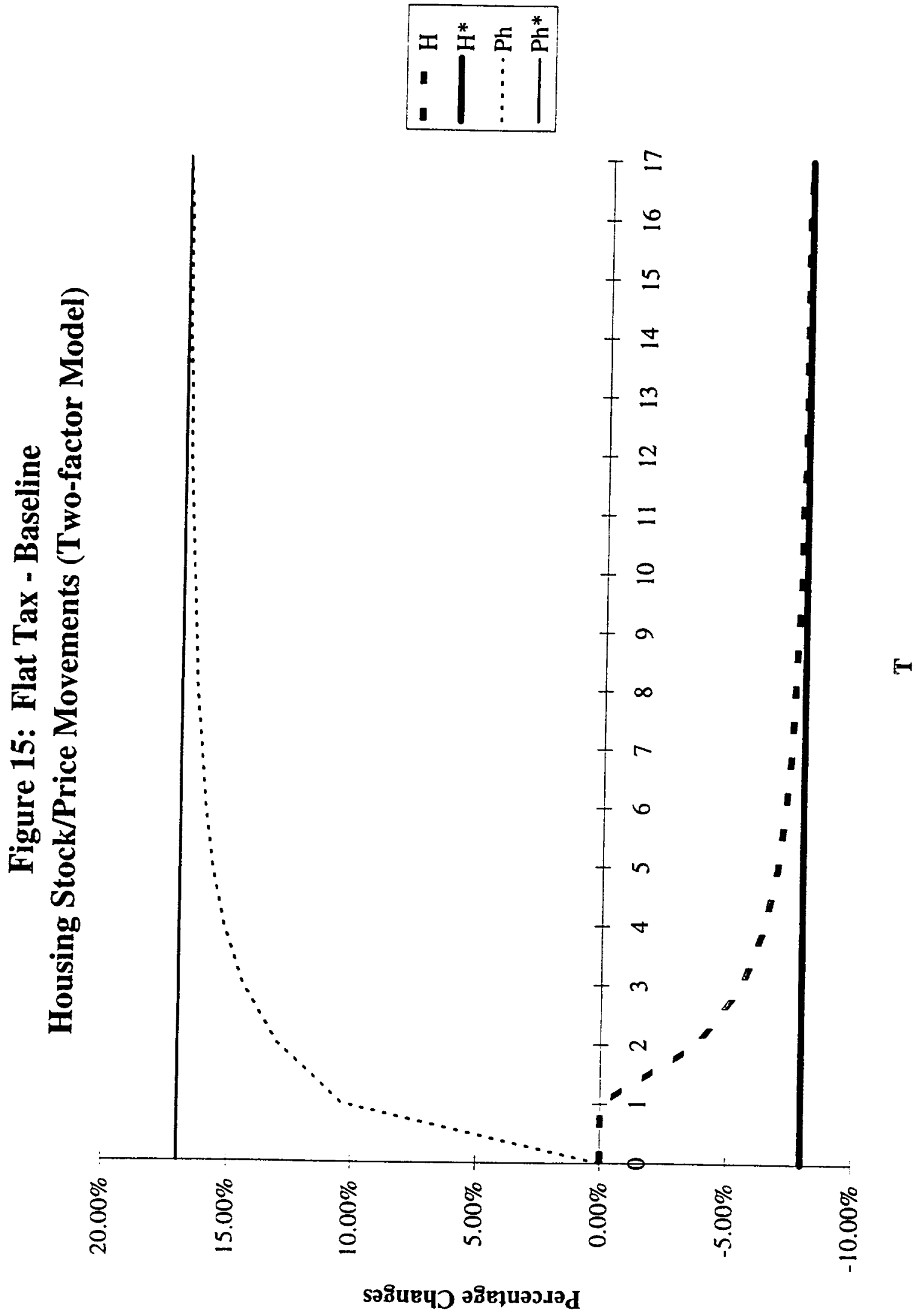
Table 1. Parameter Values

\begin{tabular}{lcc}
\hline & Panel A & \\
\hline \multicolumn{1}{c}{ Parameter } & Value \\
\hline Property Tax Rate $\left(\mathrm{t}_{\mathrm{p}}\right)$ & 0.014 \\
Initial Period Housing Service Flow $\left(\mathrm{S}_{\mathrm{o}}\right)$ & 15,000 \\
Housing Supply Elasticity $(\epsilon)$ & 0.8 \\
Housing Service Flow Elasticity $(\eta)$ & -2.0 \\
Maintenance and Depreciation $(\mathrm{m}+\delta)$ & 0.03
\end{tabular}

Panel B

\begin{tabular}{lccc}
\hline & Original & $\begin{array}{c}\text { Remove } \\
\text { Deductibility }\end{array}$ & Flat Tax \\
\hline Interest Rate $(i)$ & 0.075 & 0.075 & 0.075 \\
Average Marginal Income Tax Rate $(\tau)$ & 0.220 & 0.194 & 0.170 \\
Percent of Mortgage Interest Deductible $(\theta)$ & 0.600 & 0.000 & 0.000 \\
Percent of Property Tax Deductible $(\gamma)$ & 0.600 & 0.000 & 0.000 \\
Loan-to-Value Ratio $(\beta)$ & 0.400 & 0.400 & 0.400 \\
$\mathrm{Q}_{\mathrm{H}}$ & 1.000 & 1.000 & 1.170 \\
Percent of Interest Income Taxable $(e)$ & 0.500 & 0.500 & 0.000 \\
\hline
\end{tabular}




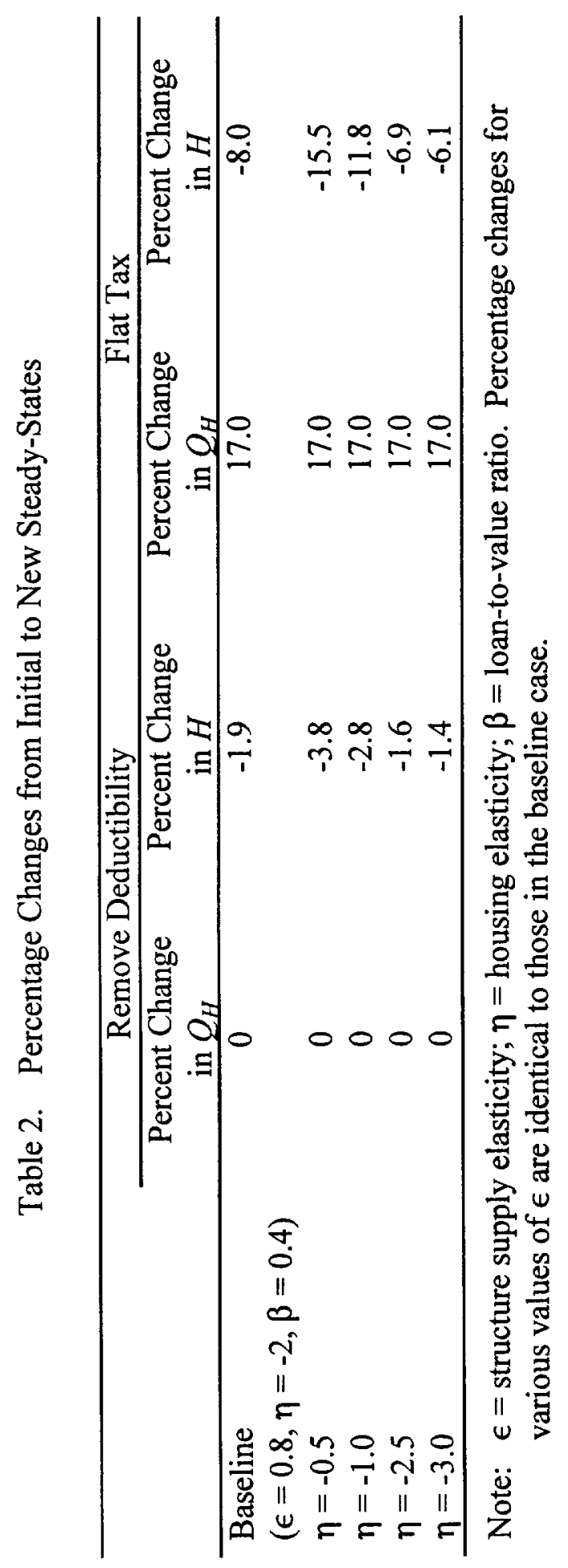

